\title{
Geo-Visualisation and Visual Analytics for Smart Cities: A Survey
}

\author{
S. Harbola ${ }^{1, *}$, V. Coors ${ }^{1}$ \\ ${ }^{1}$ Geoinformatices, Hochschule für Technik Stuttgart, Stuttgart, Germany, - (shubhi.harbola, volker.coors)@ hft-stuttgart.de
}

KEY WORDS: Geo-visualisation, Data analytics, Spatial data, Smart cities, User interaction.

\begin{abstract}
:
Geo-Visualisation (GV) and Visual Analytics (VA) of geo-spatial data have become a focus of interest for research, industries, government and other organisations for improving the mobility, energy efficiency, waste management and public administration of a smart city. The geo-spatial data requirements, increasing volumes, varying formats and quality standards, present challenges in managing, storing, visualising and analysing the data. A survey covering GV and VA of the geo-spatial data collected from a smart city helps to portray the potential of such techniques, which is still required. Therefore, this survey presents GV and VA techniques for the geo-spatial urban data represented in terms of location, multi-dimensions including time, and several other attributes. Further, the current study provides a comprehensive review of the existing literature related to GV and VA from cities, highlighting the important open white spots for the cities' geo-spatial data handling in term of visualisation and analytics. This will aid to get a better insight into the urban system and enable sustainable development of the future cities by improving human interaction with the geospatial data.
\end{abstract}

\section{INTRODUCTION}

A smart city is where contributions in human and social capital, traditional and modern infrastructure encourage sustainable economic growth and high standards of living with wise management of the natural resources (Galbrun and Miettinen, 2012, Lwin et al., 2014, Škrjanc and Mladeni, 2014, Caragliu et al., 2015, Herle et al., 2016). Some measurable indicators of the smart city are smart mobility, smart environment, smart living, smart people and smart governance with the efficient collection, interactive visualisation and analysis of the city's data, coordinated well with internet and web-based services (Portmann et al., 2017).

Further, the smart city generates spatial information based on sensors e.g., Global Navigation Satellite System (GNSS), Light Detection and Ranging (LiDAR), Synthetic Aperture Radar (SAR), Unmanned Aerial Vehicle (UAV) that collect large set of real time geo-spatial data stream and response (Nam and Pardo, 2011, Rodriguez et al., 2012, Daron et al., 2015). The geo-spatial data includes cities, rivers, roads, countries, i.e., the knowledge of the surrounding and finds increasing use in environmental monitoring, space and cities planning and resource management (Rueda and Gertz, 2008, Li et al., 2016). Moreover, the geospatial data is a geographical entity which is georeferenced and is represented in terms of location, dimensions, attributes and comprises of points, lines, areas, surfaces, volumes as well as includes time as data of higher dimension (Papadimitriou et al., 1999, Feng et al., 2012, Stasch et al., 2012, Bröring and Reitz, 2014, Gong et al., 2015, Songnian Li et al., 2016).

The geo-spatial data visualisation is a powerful instrument for interactive Visual Analytics (VA) and places the geo-spatial data in a visual context by identifying trends, patterns, that usually go unrecognised in the text-based data (Nittel, 2014, Sun and Sang, 2014, Sun and Li, 2016). Further, Geo-Visualisation (GV) techniques help in representing the geo-spatial data beyond the typical spreadsheets, charts and graphs along with presenting it in more sophisticated formats using infographics, maps, detailed bars, pie and fever charts, sparklines, heat maps and $3 \mathrm{D}$ globes to communicate relationships between the geo-spatial data values. Moreover, VA combines automated analysis techniques with interactive GV thereby assisting in the easier understanding of the geo-spatial data along with decision-making capabilities by dividing the cities into several components varying over space, time and different spatial scales (Aigner, 2013, Kehrer and Hauser, 2013, Aigner, 2015).

GV and VA collectively help in cooperation and interaction between different entities of the smart city and provide various services that help in better customers' experiences and growth prospects (Stratigea et al., 2015, Hashem et al., 2016). GV and VA together have a predominant potential for many social applications like disaster response, disease surveillance, climate change, weather monitoring and forecasting, infrastructure management, transportation and navigation, in the smart city (Cook et al., 1997, Arentze and Timmermans, 2000, Urban et al., 2009, Hlawatsch et al., 2011, MacEachren and Kraak, 2011, Hlawatsch et al., 2011, Andrienko et al., 2016, Castermans et al., 2016, Wendel, 2016). Thus, there is a need for research on effective solutions and planning of smart cities to become smarter, taking into account the resources that are available and capable of innovation (Osmanoğlu et al., 2016, Toth and Jóźków, 2016, Zhou and Weiskopf, 2017).

A number of survey papers have explored the aspects of the GV and VA separately (Kapler and Wright, 1997, Silva and Catarci, 2000, Ma and Muelder, 2013, Liu et al., 2017, Rautenhaus et al., 2017) as well as in combination, related to the multivariate, meteorological constraints, multidimensional and parallel coordinates data (Kehrer and Hauser, 2013, Gong et al., 2015, McFerren and Van Zyl, 2016, Castermans et al., 2016). Some surveys on modelling and visualising multiple geo-spatial uncertainties are also present (Davis and Keller, 1997, Ehlschlaeger et al., 1997, Li et al., 2007, Wu et al., 2012, Liu et al., 2017). However, a comprehensive survey that reviews the current research on GV and VA for the geo-spatial data from smart cities is still required and this motivates to write the current survey paper with the following contributions:

\footnotetext{
* Corresponding author
} 
i. To cover $\mathrm{GV}$ from the area of display design, 3D visualisation, comparative visualisation and data fusion, along with interactive VA and give geo-spatial data researchers a thorough picture of the existing GV and VA techniques and applications for varieties of datasets, thereby helping in frontier research and development.

ii. To present information for improving the smart cities along with the better understanding of the cities' systems through regular geo-spatial data monitoring and maintenance.

iii. To identify important open issues and challenges in the cities geo-spatial data visualisation and analytics.

\section{METHODOLOGY}

\subsection{Geo-visualisation}

Data visualisation can be categorised into three groups, namely, information visualisation, scientific visualisation and geovisualisation depending on the type of the data. Information visualisation helps in visualisation of abstract data, scientific visualisation covers spatial data and GV incorporates both the abstract and the spatial data. Figure 1 shows the real world examples that can be resolved using these techniques (Maceachren et al., 2005).

\begin{tabular}{|c|c|c|c|c|}
\hline \multicolumn{3}{|c|}{ Towards Inf ormation Visualisation } & \multicolumn{2}{|c|}{ Tow ards Scientific Visualisation } \\
\hline News Data & I ocations & Urban data for & Movement data & Flow data \\
\hline $\begin{array}{l}\text { (e.g. social } \\
\text { media) }\end{array}$ & $\begin{array}{l}\text { (e.g cities, } \\
\text { organiz ations, homes) }\end{array}$ & $\begin{array}{l}\text { (e.g buildings, } \\
\text { roads, } \\
\text { populations) }\end{array}$ & $\begin{array}{l}\text { (e.g. hurricanes, } \\
\text { animals, traffic) }\end{array}$ & $\begin{array}{l}\text { (e.g. wind, } \\
\text { temperature) }\end{array}$ \\
\hline
\end{tabular}

Figure 1. Real world examples of visualisation (Maceachren et al., 2005)

GV integrates approaches from visualisation in Scientific Computing (ViSC), cartography, image analysis, information visualisation, Exploratory Data Analysis (EDA) and Geographic Information Systems (GIS) (Otto et al., 2010, Andrienko et al., 2011, Ramathan et al., 2013, Objectives and Words, 2013, Chen et al., 2014). A city's geo-spatial data is collected using traditional techniques like surveying, photogrammetry and advanced techniques like GNSS, LiDAR, SAR and UAV and can vary from small to large volumes (Komninos et al., 2013, Bhattacharya and Painho, 2016). Common types of the geospatial data are: i) point-data, e.g. crime cases, ii) continuous values and discrete distributions, e.g. earthquake readings, iii) continuous values and continuous distributions, e.g. climate simulation data. Table 1 shows the various domains and corresponding examples of the georeferenced data.

Table 1. Georeferenced data present in various domains

\begin{tabular}{|l|l|}
\hline Domain & Example of Georeferenced data \\
\hline Daily life & Position, destination, routes \\
\hline Demographics & $\begin{array}{l}\text { Population, employment, crime } \\
\text { rate by areas, regions }\end{array}$ \\
\hline Urban planning & $\begin{array}{l}\text { Growth rate, architecture, } \\
\text { district types }\end{array}$ \\
\hline Transportation/Logistics & $\begin{array}{l}\text { Location of assets, delivery } \\
\text { networks }\end{array}$ \\
\hline Security/Intelligence & $\begin{array}{l}\text { Location and movement of } \\
\text { suspects }\end{array}$ \\
\hline
\end{tabular}

\begin{tabular}{|l|l|}
\hline Medicine/Epidemics & Region of reported infections \\
\hline Climatology/Meteorology & $\begin{array}{l}\text { Weather, regional climate } \\
\text { changes, pollution }\end{array}$ \\
\hline
\end{tabular}

GV consists of six main modules: data transformation and analysis, filtering, mapping, rendering and interactive user involvement. The collected large data can be in structured form as well as in complex form (i.e. semi-structured, unstructured, spatial, temporal and multimedia). The data transformation and analysis is tasked with extracting the structured data from the large input data (Maceachren and Kraak, 2001, Thomson et al., 2005, MacEachren and Kraak, 2011, Maciejewski et al., 2010, Maceachren et al., 2012). For the complex form data, the data mining techniques like clustering can be used to extract the related structured data for visualisation (Southworth and Peterson, 2000). Filtering module corrects the structured data for noise by applying smoothening filters, for missing values by applying interpolation techniques and for measurement errors (Church and Cova, 2000, Johnson, 2004, Chan, 2006). These corrections automatically select the key data for visualisation (Arentze and Timmermans, 2000, Dasgupta and Kosara, 2011, Dasgupta et al., 2012, Kitchin, 2013, Bröring and Reitz, 2014, Allison, 2017). After filtering, the data is mapped to geometric primitives like points, lines, regions and may have several attributes like colour, texture, position, size. Users can transform the geometric data into image data using the rendering module and interact with the generated images through various interactive controls to explore and understand the data from different perspectives (Adhianto et al., 2010, Huang et al., 2012, Hofmann et al., 2012). Moreover, interactive analysis and visualisation are driven by the applications and solutions in the domain it is applied (Trindade et al., 2017, Bharath et al., 2017) and as a result, research in this field is usually motivated by real world user requirements and desired output (Claessen and Van Wijk, 2011, Lloyd and Dykes, 2011, Chen et al., 2014, Design and Quarter, 2015, Cao and Cui, 2016).

The geo-spatial data can be visualised in 3D as 3D globes, vector maps or by rendering to 2D maps (Sugumaran and Sugumaran, 2007). 3D views provide realistic visualisations and help in comprehensive city planning activities such as flood modelling or the visibility impacts and clarity of new development (ESRI, 2014, Helfert et al., 2015, Stratigea et al., 2015). The 3D urban maps and the associated building models can also be combined with several established disciplines, including engineering Computer-Aided Drafting (CAD), architectural Building Information Management (BIM), and GIS (Samson and Lu, 2016, Furmanova et al., 2017). The detailed building information, physical and functional characteristics all portrayed in the urban 3D map in connection with the geographic location hence become an important feature of smart city Spatial Data Infrastructure (SDI) (Gröger and Plümer, 2012, Huang and Liang, 2014, Stratigea et al., 2015, Panagiotopoulou and Stratigea, 2017). This collective urban map, if fully built and attributed, enables a high degree of understanding of the complete urban environment and facilitates an enhanced ability to plan and manage events while providing interactive visual decision making. However, even if partially complete, 3D maps with key attributes enable significant advances over traditional 2D applications. Examples of maps are, twitter message location, traffic control and 3D urban model (Songnian Li et al., 2016, Andrienko et al., 2016). Further, 3D maps can be projected to 2D by using projections such as simple-cylindrical, Lambert, Mercator, conical etc. along with defining the anatomy of maps for framing the map design (Haywood et al., 2013, Haywood et al., 2016). Generalisation of the map is a method for deriving a smaller scale map from larger scale map. The process of 
generalisation abstract the geo-spatial information at a high level of detailed information that meets the users' requirements (Jones and Ware, 2007, Burghardt, 2014).

The techniques that can be used for visualising sensor's data are scatter plot, heat maps, height maps, survey plot, logic diagrams, parallel coordinates, multiple line graph, sammon plots and multi-dimensional scaling, polar charts, principal component and principal curve analysis, logic diagrams, choropleth maps, isolines, tilevis, plume chart, dashboards, quartile chart, trees, network and glyphs. Del Fatto et al. (2007) give schematized representations of territories i.e. chorems, for visual summary of spatial databases. Moreover, combining time and space, provides temporal and geo-spatial correlation and helps in interactive temporal visualisation and examples of these are population development over time, epidemic spread over time and movements (traffic, animals, pedestrians, hurricanes, particles) (Sun et al., 2013, Sun and Li, 2016). Table 2 gives the difference between visualising time, space separately (Table 2 , first column) and in combination (Table 2, second column). Mapping time to space can be achieved using three methods, (i) separate views of each and interaction by brushing and linking, (ii) space-time cube where third axis represents time, (iii) animation involving time.

Table 2. The difference between the separate view and space time combined view

\begin{tabular}{|l|l|}
\hline Separate view & Space time combined view \\
\hline $\begin{array}{l}\text { Clear and causal interactions } \\
\text { (navigate, select, manipulate) }\end{array}$ & $\begin{array}{l}\text { Complicated 3D interaction } \\
\text { in 2D environment }\end{array}$ \\
\hline $\begin{array}{l}\text { Gives an undistorted view on } \\
\text { the geo-spatial. Clutter } \\
\text { reduction, good visual } \\
\text { scalability due to separation }\end{array}$ & $\begin{array}{l}\text { Additional clutter and } \\
\text { occlusion in 3D cube, bad } \\
\text { visual scalability. } \\
\text { Perspective distortion. }\end{array}$ \\
\hline $\begin{array}{l}\text { Spatio-temporal overview } \\
\text { not available }\end{array}$ & $\begin{array}{l}\text { Spatio-temporal overview } \\
\text { available }\end{array}$ \\
\hline $\begin{array}{l}\text { Spatio-temporal correlation } \\
\text { difficult to identify }\end{array}$ & $\begin{array}{l}\text { Spatio-temporal correlation } \\
\text { easily identified }\end{array}$ \\
\hline
\end{tabular}

The management of the geo-spatial data is also an important aspect for visualizing the georeferenced data collected from the cities because different sensors measure more than one kind of data at a time and may cover a large area, thus displaying all sensors value is difficult. GIS manages geographically referenced information and aids in the geo-visualisation by analysing, managing and displaying the geo-spatial data and is also supported by SDI for both static and real time data (Figure 2). Integrating the GIS with the web (i.e. Web-GIS) enhances the interactivity of users with maps and improves spatial analysis as shown in Figure 2 (Goodchild, 2007, Goodchild, 2013, Holliman et al., 2017). The two types of geo-spatial data management models can be represented either by raster or vector data models (You and Kim, 2000, Huang and Liang, 2014, Stefan et al., 2017).

The Open Geospatial Consortium (OGC) with its Senor Web Enablement (SWE) initiative passed the standards to control, detect and receive sensor data and some examples are, Sensor Observation Service (SOS) designed for 2D data and dynamic 3D SDIs for 3D data. OGC sensor web enabled open architecture makes it possible to handle most types of sensors (Mayer and Zipf, 2009, Prandi et al., 2013). Web based Spatial Decision Support System (SDSS/WebSDSS) helps to solve complex geospatial data problems relating to urban planning, site selection and decision making (Figure 2). A WedSDSS includes problem solver web-based GIS and geographic data retrieval facilities, analysis and display (Sugumaran and Sugumaran, 2007). Recently multidimensional distributed spatial platform integrating sensor web with SDIs, Smart Cities Intelligence
System (SMACiSYS) has been developed (Bhattacharya and Painho, 2017).

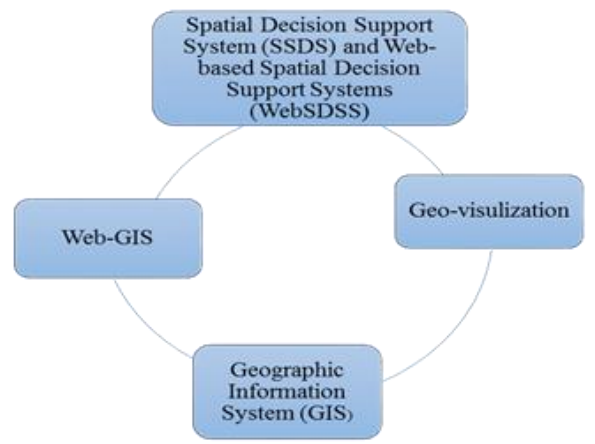

Figure 2. Data management and visualisation techniques and tools

\subsection{Visual analytics}

Digital visualisation gives an effective medium to analyse, but it is VA that aids in the design of the cities (Marsal-Llacuna et al., 2015, Marsal-Llacuna and Segal, 2016). VA transcends the pictorial representations and links the various tasks to appeal visually as well as reflects the quality and efficacies of the urban design (Gröger and Plümer, 2012, Albino et al., 2015, Bharath et al., 2017). Table 3 lists some examples of services available in the smart cities and the corresponding use of VA.

Table 3. Available services in the smart cities and the corresponding role of VA (Fernández-Prieto et al., 2014)

\begin{tabular}{|l|l|}
\hline \multicolumn{1}{|c|}{ Services } & \multicolumn{1}{|c|}{ VA } \\
\hline $\begin{array}{l}\text { Maintenance } \\
\text { and } \\
\text { management of } \\
\text { asset }\end{array}$ & $\begin{array}{l}\text { Asset performance index, optimal } \\
\text { intervention point analytic }\end{array}$ \\
\hline $\begin{array}{l}\text { Connected and } \\
\text { involved } \\
\text { citizens }\end{array}$ & $\begin{array}{l}\text { Citizens satisfaction levels, citizens } \\
\text { awareness levels index }\end{array}$ \\
\hline $\begin{array}{l}\text { Infrastructure } \\
\text { based on sensors }\end{array}$ & $\begin{array}{l}\text { Data quality index, transportation } \\
\text { conditions index, traffic forecast }\end{array}$ \\
\hline $\begin{array}{l}\text { Smart land-use } \\
\text { Observed rates for different land uses and } \\
\text { travel between zones, land value } \\
\text { transportation index, zone accessibility } \\
\text { index }\end{array}$ \\
\hline $\begin{array}{l}\text { Business models } \\
\text { strategy and } \\
\text { partnering }\end{array}$ & $\begin{array}{l}\text { Percentage of private sector investment, } \\
\text { number of partnerships, improvement in } \\
\text { service delivery, private-public sector } \\
\text { interaction and money invested }\end{array}$ \\
\hline $\begin{array}{l}\text { Urban } \\
\text { automation }\end{array}$ & $\begin{array}{l}\text { Percentage of automated vehicles within } \\
\text { the entire citywide convoy, percentage of } \\
\text { automated vehicles in use by city public } \\
\text { and private groups, proportion of } \\
\text { deliveries made by automated vehicles, } \\
\text { proportion of passengers carried by } \\
\text { automated transit. }\end{array}$ \\
\hline $\begin{array}{l}\text { User centric } \\
\text { mobility }\end{array}$ & $\begin{array}{l}\text { Citywide mobility index, user satisfaction } \\
\text { index, transportation service delivery } \\
\text { reliability index }\end{array}$ \\
\hline
\end{tabular}

In designing an interactive urban VA, there are generally four essential features of VA, involved in the smart design of a city. First is the geo-visualisation of the city design in 3D or 2D maps and transforming into several virtual environments to aid city designers and users to experience the design ( $\mathrm{Fu}$ and Zhang, 
2017). The second feature is the layout of the networks for understanding the interaction among users and their movement (Tan et al., 2017). The third feature involves social media that reflects the users' communication in the real and virtual design of the city (Ahvenniemi et al., 2017). The fourth feature deals with the planning process based on the online information where users contribute to the improvement of the designs and generating more data (Kumar and Prakash, 2013).

\subsection{GV and VA in smart cities: Applications}

GV and VA tools and methods encourage collaboration and communication between entities and provide services to many sectors in the smart city, as well as improve customer's experiences and business opportunities (Hashem et al., 2016, Data et al., 2017). The solutions found in the recent literature can be classified into the following categories: smart grids, smart healthcare, smart transportation, smart governance. Smart grids have enabled researchers to integrate, analyse, and use real-time power generation and consumption data, as well as other types of environmental data (Nga et al., 2012, He et al., 2015, Overbye and Weber, 2015, Tsolakis and Anthopoulos, 2015, Zhou et al., 2016, Sanchez and Rivera, 2017, Stefan et al., 2017).

Smart healthcare related analytics tools allow healthcare specialists to collect and analyse patients' data, which can likewise be used by insurance agencies and administration organisations. Moreover, proper analytics of large healthcare data can help predict epidemics, cures, and diseases, as well as improve quality of life and avoid preventable death (Noon and Hankins, 2001, Vanus et al., 2014, Jeong et al., 2016, Mahmud et al., 2016, Marsal-Llacuna and Segal, 2016, Kunjir et al., 2017, Muhammad Babar, 2017, Tunio et al., 2017).

Smart transportation provides VA applications to visualise and analyse a large amount of data collected from transportation system, thereby helping in the improvement of the transportation systems in terms of minimizing traffic congestion, by providing alternative routes and reducing the number of accidents through the analyses of the history of mishaps, including factors such as their cause and the driver speed (Claramunt et al., 2000, Gröger and Plümer, 2012, Andrienko, 2013, Krüger et al., 2013, Objectives and Words, 2013, Exner, 2015, Yinhai Wang et al., 2016, Yun Wang et al., 2016, Kalamaras et al., 2017, Kurkcu et al., 2017). Singh et al., (2017) proposed a framework of interactive VA for detecting bike-riders without helmet, automatically in city traffic.

Smart governance data analytics can help governments establish and implement satisfactory policies taking into consideration the needs of the people in terms of health, social care and education. In addition, the ratio of unemployment can also be reduced by analysing the large data of different educational institutes (Best and Lewis, 2010, Nam and Pardo, 2011, Graves and Hendler, 2013, Al Nuaimi et al., 2015, Götz and Schäffler, 2015, Tsolakis and Anthopoulos, 2015, Lara et al., 2016, H. Li et al., 2016, S. Li et al., 2016, Allison, 2017, Kudva and Ye, 2017, Wang et al., 2017). Thomas and Cook, (2005, 2006) worked with US Department of Homeland Security (DHS) and chartered the National Visulisation and Analytics Center (NVAC) to counter future terrorist attacks in the USA and around the globe. Kohlhammer et al. (2010) proposed information visualisation and VA for governance and policy modelling. Similarly, Trento i-scope project deals with citizen participation for web based services in order to reproduce cities (http://crowdcity.com/). Smartmap Berlin (http://www.businesslocationcenter.de/smartmap-berlin) provides visualisation and analysis of Berlin in photorealistic 3D format. In strengthening the smart governance application attempts of the city modelling in focus to match with the emerging practices of eco-town based urban developments have been implemented in Germany, Netherlands, Sweden and example smart city initiatives from Korea (Bayulken and Huisingh, 2015, Yigitcanlar and Kamruzzaman, 2015).

\section{CHALLENGES AND CONCLUSION}

In this paper, the GV and VA techniques incorporating the geospatial data from the smart cities, have been surveyed. The GV along with VA aid in better understanding of the geo-spatial data by identifying trends, patterns and contexts and make economy, mobility, environment, people and governance of a city smarter. This paper with a comprehensive review of current research will provide researchers with the guidelines in GV and VA for smart cities planning and applications. In future, error and uncertainty in visualisation and analytics techniques along with the handling of real time geo-spatial data streams will be further explored and also with the focus on VA in windy cities, especially at the strategic planning level.

\section{REFERENCES}

Adhianto, L., Banerjee, S., Fagan, M., Krentel, M., Marin, G., Mellor-Crummey, J., Tallent, N.R., 2010. HPCTOOLKIT: Tools for performance analysis of optimized parallel programs. Concurr. Comput. Pract. Exp. 22, 685-701. https://doi.org/10.1002/cpe

Ahvenniemi, H., Huovila, A., Pinto-Seppä, I., Airaksinen, M., 2017. What are the differences between sustainable and smart $\begin{array}{llll}\text { cities. } & \text { Cities } & 60, & 234-245 .\end{array}$ https://doi.org/10.1016/j.cities.2016.09.009

Aigner, W., 2013. Interactive visualization and data analysis: visual analytics with a focus on time.

Al Nuaimi, E., Al Neyadi, H., Mohamed, N., Al-Jaroodi, J., 2015. Applications of big data to smart cities. J. Internet Serv. Appl. 6, 1-15. https://doi.org/10.1186/s13174-015-0041-5

Albino, V., Berardi, U., Dangelico, R.M., 2015. Smart cities: Definitions, dimensions, performance, and initiatives. J. Urban Technol. 22 ,

$1-19$.

https://doi.org/10.1080/10630732.2014.942092

Andrienko, G., Andrienko, N., Dykes, J., Kraak, M.J., Robinson, A., Schumann, H., 2016. GeoVisual analytics: Interactivity, dynamics, and scale. Cartogr. Geogr. Inf. Sci. 43, 1-2. https://doi.org/10.1080/15230406.2016.1095006

Andrienko, G., Andrienko, N., Keim, D., MacEachren, A.M., Wrobel, S., 2011. Challenging problems of geospatial visual analytics. J. Vis. Lang. Comput. 22, 251-256. https://doi.org/10.1016/j.jvlc.2011.04.001

Arentze, T.A., Timmermans, H.J.P., 2000. A spatial decision support system for retail plan generation and impact assessment. Transp. Res. Part C Emerg. Technol. 8, 361-380. https://doi.org/10.1016/S0968-090X(00)00010-3

Bayulken, B., Huisingh, D., 2015. Are lessons from eco-towns helping planners make more effective progress in transforming cities into sustainable urban systems: A literature review (part 2

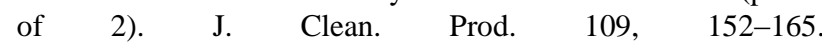
https://doi.org/10.1016/j.jclepro.2014.12.099 
Best, D.M., Lewis, R.R., 2010. GWVis: A tool for comparative ground-water data visualization. Comput. Geosci. 36, 14361442. https://doi.org/10.1016/j.cageo.2010.04.006

Bharath, H.A., Vinay, S., Ramachnadra, T.V., 2017. Characterization and visualization of spatial patterns of urbanisation and sprawl through metrics and modeling. Cities Environ. 10, 33

Bhattacharya, D., Painho, M., 2016. Design for connecting spatial data infrastructures with sensor web (Sensdi). ISPRS Ann. Photogramm. Remote Sens. Spat. Inf. Sci. III-4, 33-39. https://doi.org/10.5194/isprsannals-III-4-33-2016

Bröring, A., Reitz, T., 2014. Processing real-time sensor data streams for 3D web visualization. 5th IWGS Work. @ ACM Sigspatial 1-8. https://doi.org/10.1145/2676552.2676556

Burghardt, D., 2014. Abstracting geographic information in a data rich world methodologies and applications of map generalisation 407. https://doi.org/10.1007/978-3-319-00203-3 Cao, N., Cui, W., 2016. Introduction to text visualization. https://doi.org/10.2991/978-94-6239-186-4

Caragliu, A., Bo, C. Del, Nijkamp, P., 2015. Smart cities in europe smart cities in europe 0732, 45-59. https://doi.org/10.1080/10630732.2011.601117

Castermans, T., Speckmann, B., Verbeek, K., Westenberg, M.A., Betti, A., Van Den Berg, H., 2016. GlamMap: Geovisualization for e-Humanities

Chan, W.W., 2006. A Survey on multivariate data visualization. Sci. Technol. 1-29. https://doi.org/10.1145/1330598.1330687

Chen, M., Mao, S., Liu, Y., 2014. Big data: A survey. Mob. Networks Appl. 19, 171-209. https://doi.org/10.1007/s11036013-0489-0

Church, R.L., Cova, T.J., 2000. Mapping evacuation risk on transportation networks using a spatial optimization model. Transp. Res. Part C Emerg. Technol. 8, 321-336. https://doi.org/10.1016/S0968-090X(00)00019-X

Claessen, J.H.T., Van Wijk, J.J., 2011. Flexible linked axes for multivariate data visualization. IEEE Trans. Vis. Comput. Graph. 17, 2310-2316. https://doi.org/10.1109/TVCG.2011.201

Claramunt, C., Jiang, B., Bargiela, A., 2000. A new framework for the integration, analysis and visualisation of urban traffic data within geographic information systems. Transp. Res. Part C Emerg. Technol. 8, 167-184. https://doi.org/10.1016/S0968090X(00)00009-7

Cook, D., Symanzik, J., Majure, J.J., Cressie, N., 1997. Dynamic graphics in a GIS: More examples using linked software. Comput. Geosci. 23, 371-385. https://doi.org/10.1016/S00983004(97)00015-0

Daron, J.D., Lorenz, S., Wolski, P., Blamey, R.C., Jack, C., 2015. Interpreting climate data visualisations to inform adaptation decisions. Clim. Risk Manag. 10, 17-26. https://doi.org/10.1016/j.crm.2015.06.007

Dasgupta, A., Kosara, R., 2011. Adaptive privacy-preserving visualization using parallel coordinates. IEEE Trans. Vis.
Comput. Graph. 17, 2241-2248. https://doi.org/10.1109/TVCG.2011.163

Dasgupta, A., Chen, M., Kosara, R., 2012. Conceptualizing visual uncertainty in parallel coordinates. Comput. Graph. Forum 31, 1015-1024. https://doi.org/10.1111/j.14678659.2012.03094.x

Data, B., Life, T.O., Better, F.O.R., 2017. Immersive data visualization for smart cities.

Davis, T.J., Keller, C.P., 1997. Modelling and visualizing multiple spatial uncertainties. Comput. Geosci. 23, 397-408. https://doi.org/10.1016/S0098-3004(97)00012-5

Del Fatto, V., Laurini, R., Lopez, K., Loreto, R., Milleret-Raffort, F., Sebillo, M., Sol-Martinez, D., Vitiello, G., 2007. Potentialities of chorems as visual summaries of geographic databases contents. Proc. 9th Int. Conf. Adv. Vis. Inf. Syst. 537-548

Design, C., Quarter, G.W., 2015. Lecture 3: Thematic cartography, geovisualization and visual analytics thematic cartography

Ehlschlaeger, C.R., Shortridge, A.M., Goodchild, M.F., 1997. Visualizing spatial data uncertainty using animation. Comput. Geosci. 23, 387-395. https://doi.org/10.1016/S00983004(97)00005-8

ESRI, 2014. 3D Urban Mapping: from pretty pictures to 3D GIS 13

Exner, J.-P., 2015. Smart Cities - Field of application for Planning Support Systems in the 21st Century, 14th Comput. Urban Plan. Urban Manag. 118-131

Feng, K.C., Wang, C.L., Shen, H.W., Lee, T.Y., 2012. Coherent time-varying graph drawing with multifocus plus context interaction. Ieee Trans. Vis. Comput. Graph. 18, 1330-1342. https://doi.org/10.1109/tvcg.2011.128

Fernández-Prieto, D., Zeckzer, D., Hernandez, J.T., 2014. UCIV 4 Planning: A user-centered approach for the design of interactive visualizations to support urban and regional planning. IADIS Int. J. Comput. Sci. Inf. Syst. 8, 27-39

Fu, Y., Zhang, X., 2017. Trajectory of urban sustainability concepts: A 35-year bibliometric analysis. Cities 60, 113-123. https://doi.org/10.1016/j.cities.2016.08.003

Furmanova, K., Gratzl, S., Stitz, H., Zichner, T., Jaresova, M., Ennemoser, M., Lex, A., Streit, M., 2017. Taggle: Scalable visualization of tabular data through aggregation $1-14$

Galbrun, E., Miettinen, P., 2012. A case of visual and interactive data analysis: Geospatial redescription mining. ECML PKDD 2012 Work. Instant Interact. Data Min. (pp.1-12), Antwerpen, Belgium

Gong, J., Geng, J., Chen, Z., 2015. Real-time GIS data model and sensor web service platform for environmental data management. Int. J. Health Geogr. 14, 2. https://doi.org/10.1186/1476-072X$14-2$

Goodchild, M.F., 2013. The quality of big (geo)data. Dialogues Hum. Geogr. 3, 280-284. https://doi.org/10.1177/2043820613513392 
Goodchild, M.F., 2007. Citizens as sensors: The world of volunteered geography. GeoJournal 69, 211-221. https://doi.org/10.1007/s10708-007-9111-y

Götz, G., Schäffler, A., 2015. Conundrums in implementing a green economy in the Gauteng City-Region. Curr. Opin. Environ. Sustain. 13, 79-87. https://doi.org/10.1016/j.cosust.2015.02.005

Graves, A., Hendler, J., 2013. Visualization tools for open government data. Proc. 14th Annu. Int. Conf. Digit. Gov. Res. dg.o '13 136. https://doi.org/10.1145/2479724.2479746

Gröger, G., Plümer, L., 2012. CityGML - Interoperable semantic 3D city models. ISPRS J. Photogramm. Remote Sens. 71, 12-33. https://doi.org/10.1016/j.isprsjprs.2012.04.004

Hashem, I.A.T., Chang, V., Anuar, N.B., Adewole, K., Yaqoob, I., Gani, A., Ahmed, E., Chiroma, H., 2016. The role of big data in smart city. Int. J. Inf. Manage. 36, 748-758. https://doi.org/10.1016/j.ijinfomgt.2016.05.002

Haywood, A.M., Dolan, A.M., Pickering, S.J., Dowsett, H.J., McClymont, E.L., Prescott, C.L., Salzmann, U., Hill, D.J., Hunter, S.J., Lunt, D.J., Pope, J.O., Valdes, P.J., 2013. On the identification of a Pliocene time slice for data-model comparison. Philos. Trans. R. Soc. A Math. Phys. Eng. Sci. 371, $20120515-$ 20120515. https://doi.org/10.1098/rsta.2012.0515

Haywood, A.M., Dowsett, H.J., Dolan, A.M., Rowley, D., AbeOuchi, A., Otto-Bliesner, B., Chandler, M.A., Hunter, S.J., Lunt, D.J., Pound, M., Salzmann, U., 2016. The Pliocene Model Intercomparison Project (PlioMIP) Phase 2: Scientific objectives and experimental design. Clim. Past 12, 663-675. https://doi.org/10.5194/cp-12-663-2016

He, X., Ai, Q., qiu, R.C., Ni, J., Piao, L., Xu, Y., Xu, X., 2015. 3D Power-map for Smart Grids---An Integration of Highdimensional Analysis and Visualization 1, 1-5. https://doi.org/10.1049/cp.2015.0540

Helfert, M., Krempels, K.H., Klein, C., Donnellan, B., Gusikhin, O., 2015. Smart cities, green technologies, and intelligent transport systems: 4th international conference, Smartgreens 2015 and 1st international conference VEHITS 2015 Lisbon, Portugal, May 2015 revised selected papers. Commun. Comput. Inf. Sci. 579, 17-31. https://doi.org/10.1007/978-3-319-27753-0

Herle, S., Becker, R., Blankenbach, J., Information, G., 2016. Smart sensor-based Monitoring geospatial architecture for. https://doi.org/10.1088/1755-1315/34/1/012014

Hlawatsch, M., Leube, P., Nowak, W., Weiskopf, D., 2011. Flow radar glyphs-static visualization of unsteady flow with uncertainty. IEEE Trans. Vis. Comput. Graph. 17, 1949-1958. https://doi.org/10.1109/TVCG.2011.203

Hofmann, H., Follett, L., Majumder, M., Cook, D., 2012. Graphical tests for power comparison of competing designs. IEEE Trans. Vis. Comput. Graph. 18, 2441-2448. https://doi.org/10.1109/TVCG.2012.230

Holliman, N., Turner, M., Dowsland, S., Cloete, R., Picton, T., 2017. Designing a cloud-based 3D visualization engine for smart cities $173-178$

Huang, C., Liang, S., City, J., Cyber-, G., 2012. The challenges of constructing a sensor web data stream management System
Huang, C.Y., Liang, S., 2014. A sensor data mediator bridging the OGC Sensor Observation Service (SOS) and the OASIS Open Data Protocol (OData). Ann. GIS 20, 279-293. https://doi.org/10.1080/19475683.2014.942795

Jeong, J.S., Han, O., You, Y.Y., 2016. A design characteristics of smart healthcare system as the IoT application. https://doi.org/10.17485/ijst/2016/v9i37/102547

Johnson, C., 2004. Top scientific visualization research problems. IEEE Comput. Graph. Appl. 24, 13-17. https://doi.org/10.1109/MCG.2004.20

Jones, C.B., Ware, J.M., 2007. Map generalisation in the web age. Int. J. 19, 859-870

Kalamaras, I., Zamichos, A., Salamanis, A., Drosou, A., Kehagias, D.D., Margaritis, G., Papadopoulos, S., Tzovaras, D., 2017. An interactive visual analytics platform for smart intelligent transportation systems management. IEEE Trans. $\begin{array}{lllll}\text { Intell. } & \text { Transp. } & \text { Syst. } & 19, & 1-10\end{array}$ https://doi.org/10.1109/TITS.2017.2727143

Kapler, T., Wright, W., 1997. Geotime information visualization. inf. vis. $\quad 4, \quad 136-146$ https://doi.org/10.1057/palgrave.ivs.9500097

Kehrer, J., Hauser, H., 2013. Visualization and visual analysis of multifaceted scientific data: A survey. IEEE Trans. Vis. Comput. Graph. 19, 495-513. https://doi.org/10.1109/TVCG.2012.110

Kitchin, R., 2013. Big data and human geography: Opportunities, challenges and risks. Dialogues Hum. Geogr. 3, 262-267. https://doi.org/10.1177/2043820613513388

Kohlhammer, J., Ruppert, T., Davey, J., Mansmann, F., Keim, D., 2010. Information visualisation and visual analytics for governance and policy modelling. Eur. Comm. Futur. Res. ICT Gov. Policy Model. Crossroad - A Particip. Roadmap ICT Res. Electron. Gov. Policy Model

Komninos, N., Pallot, M., Schaffers, H., 2013. Special issue on smart cities and the future internet in Europe. J. Knowl. Econ. 4, 119-134. https://doi.org/10.1007/s13132-012-0083-x

Krüger, R., Thom, D., Wörner, M., Bosch, H., Ertl, T., 2013. TrajectoryLenses - A set-based filtering and exploration technique for long-term trajectory data. Comput. Graph. Forum 32, 451-460. https://doi.org/10.1111/cgf.12132

Kudva, S., Ye, X., 2017. Smart cities, big data, and sustainability union. big data cogn. Comput. 1, 4 https://doi.org/10.3390/bdcc1010004

Kumar, S., Prakash, A., 2013. Role of big data and analytics in smart cities. Int. J. Sci. Res. ISSN (Online Index Copernicus Value Impact Factor 14611, 2319-7064

Kunjir, A., Sawant, H., Shaikh, N.F., 2017. Data mining and visualization for prediction of multiple diseases in healthcare. Proc. 2017 Int. Conf. Big Data Anal. Comput. Intell. ICBDACI 2017 329-334. https://doi.org/10.1109/ICBDACI.2017.8070858

Kurkcu, A., Miranda, F., Ozbay, K., Silva, C.T., 2017. Data visualization tool for monitoring transit operation and performance. 2017 5th IEEE Int. Conf. Model. Technol. Intell. 
Transp.

Syst.

https://doi.org/10.1109/MTITS.2017.8005584

Lara, A.P., Moreira Da Costa, E., Furlani, T.Z., Yigitcanlar, T., 2016. Smartness that matters: towards a comprehensive and human-centred characterisation of smart cities. J. Open Innov. Technol. Mark. Complex. 2, 8. https://doi.org/10.1186/s40852016-0034-z

Li, H., Fan, H., Mao, F., 2016. A visualization approach to air pollution data exploration-A case study of air quality index (PM2.5) in Beijing, China. Atmosphere (Basel). 7. https://doi.org/10.3390/atmos7030035

Li, H., Fu, C.W., Li, Y., Hanson, A.J., 2007. Visualizing largescale uncertainty in astrophysical data. IEEE Trans. Vis. Comput. Graph. 13 , 1640-1647.

https://doi.org/10.1109/TVCG.2007.70530

Li, S., Dragicevic, S., Anton, F., Sester, M., Winter, S., Coltekin, A., Pettit, C., Jiang, B., Haworth, J., Stein, A., Cheng, T., 2016. Geospatial big data handling theory and methods: A review and research challenges. ISPRS J. Photogramm. Remote Sens. 1-25. https://doi.org/10.1016/j.isprsjprs.2015.10.012

Li, S., Dragicevic, S., Castro, F.A., Sester, M., Winter, S., Coltekin, A., Pettit, C., Jiang, B., Haworth, J., Stein, A., Cheng, T., 2016. Geospatial big data handling theory and methods: A review and research challenges. ISPRS J. Photogramm. Remote Sens. 115 119-133.

https://doi.org/10.1016/j.isprsjprs.2015.10.012

Liu, S., Wang, X., Liu, M., Zhu, J., 2017. Towards better analysis of machine learning models: A visual analytics perspective. Vis. Informatics. https://doi.org/10.1016/j.visinf.2017.01.006

Lloyd, D., Dykes, J., 2011. Human-centered approaches in geovisualization design: Investigating multiple methods through a long-term case study. IEEE Trans. Vis. Comput. Graph. 17, 2498-2507. https://doi.org/10.1109/TVCG.2011.209

Lwin, K., Hashimoto, M., Murayama, Y., 2014. Real-time geospatial data collection and visualization with smartphone. J. Geogr. Inf. Syst. 6, 99-108

Ma, K.L., Muelder, C.W., 2013. Large-scale graph visualization and analytics. Computer (Long. Beach. Calif). 46, 39-46. https://doi.org/10.1109/MC.2013.242

MacEachren, A.M., Kraak, M.J., 2011. Exploratory cartographic visualisation: Advancing the agenda. Map Read. Theor. Mapp. Pract. Cartogr. Represent. 23, 83-88. https://doi.org/10.1002/9780470979587.ch11

Maceachren, A.M., Robinson, A., Hopper, S., 2005. Visualizing geospatial information uncertainty: What we know and what we need to know. Cartogr. Geogr. Inf. Sci. 32, 139-160. https://doi.org/10.1559/1523040054738936

Maceachren, A.M., Roth, R.E., O'Brien, J., Swingley, D., Gahegan, M., 2012. Visual semiotics and uncertainty visualisation: An empirical study. IEEE Trans. Vis. Comput. Graph. 18, 1-10. https://doi.org/10.1109/TVCG.2012.279

Maciejewski, R., Rudolph, S., Hafen, R., Abusalah, A.M., Yakout, M., Ouzzani, M., Cleveland, W.S., Grannis, S.J., Ebert, D.S., 2010. A visual analytics approach to understanding spatiotemporal hotspots. Ieee Trans. Vis. Comput. Graph. 16, 205-220. https://doi.org/10.1109/tvcg.2009.100

Mahmud, S., Iqbal, R., Doctor, F., 2016. Cloud enabled data analytics and visualization framework for health-shocks prediction. Futur. Gener. Comput. Syst. 65, 169-181. https://doi.org/10.1016/j.future.2015.10.014

Marsal-Llacuna, M.L., Colomer-Llinàs, J., Meléndez-Frigola, J., 2015. Lessons in urban monitoring taken from sustainable and livable cities to better address the smart cities initiative. Technol. Forecast. Soc. Change 90, 611-622. https://doi.org/10.1016/j.techfore.2014.01.012

Marsal-Llacuna, M.L., Segal, M.E., 2016. The Intelligenter Method (I) for making "smarter" city projects and plans. Cities 55, 127-138. https://doi.org/10.1016/j.cities.2016.02.006

McFerren, G., Van Zyl, T., 2016. Geospatial data stream processing in python using FOSS4G components. Int. Arch. Photogramm. Remote Sens. Spat. Inf. Sci. - ISPRS Arch. 41, 931-937. https://doi.org/10.5194/isprsarchives-XLI-B7-9312016

Muhammad Babar, F.A., 2017. Smart urban planning using big data analytics to contend with the interoperability in internet of things. Futur. Gener. Comput. Syst. 77, 65-76. https://doi.org/10.1016/j.future.2017.07.029

Nam, T., Pardo, T.A., 2011. Conceptualizing smart city with dimensions of technology, people, and institutions. Proc. 12th Annu. Int. Digit. Gov. Res. Conf. Digit. Gov. Innov. Challenging. https://doi.org/10.1145/2037556.2037602

Nga, D.V., Quang, D.N., Xuen, C.Y., Chee, L.L., See, O.H., 2012. Visualization techniques in smart grid. 2012 Int. Conf. Smart Grid Syst. 45, 22-26.

Noon, C.E., Hankins, C.T., 2001. Spatial data visualization in healthcare: Supporting a facility location decision via GIS-based market analysis. Proc. Hawaii Int. Conf. Syst. Sci. 00, 149. https://doi.org/10.1109/HICSS.2001.926573

Objectives, L., Words, K.E.Y., 2013. Learning objectives. $\begin{array}{llll}\text { Continuum } & \text { (Minneap. } & 1179 .\end{array}$ https://doi.org/10.1212/01.CON.0000436148.93543.f9

Osmanoğlu, B., Sunar, F., Wdowinski, S., Cabral-Cano, E., 2016. Time series analysis of InSAR data: Methods and trends. ISPRS J. Photogramm. Remote Sens. 115, 90-102. https://doi.org/10.1016/j.isprsjprs.2015.10.003

Otto, M., Germer, T., Hege, H.C., Theisel, H., 2010. Uncertain 2D vector field topology. Comput. Graph. Forum 29, 347-356. https://doi.org/10.1111/j.1467-8659.2009.01604.x

Overbye, T.J., Weber, J., 2015. Smart grid wide-area transmission system visualization. Engineering 1, 466-474. https://doi.org/10.15302/J-ENG-2015098

Panagiotopoulou, M., Stratigea, A., 2017. Smart cities in the mediterranean 31-58. https://doi.org/10.1007/978-3-319-545585

Papadimitriou, C.H., Suciu, D., Vianu, V., 1999. Topological queries in spatial databases. J. Comput. Syst. Sci. 58, 29-53. https://doi.org/10.1006/jcss.1998.1597 
Portmann, E., Finger, M., Engesser, H., 2017. Smart cities. Informatik-spektrum 40, 1-5. https://doi.org/10.1007/s00287016-1000-7

Ramathan, A., Dykes, J., Wood, J., 2013. Framework for studying spatially ordered treemaps $25-30$

Rautenhaus, M., Bottinger, M., Siemen, S., Hoffman, R., Kirby, R.M., Mirzargar, M., Rober, N., Westermann, R., 2017. Visualization in meteorology --- A survey of techniques and tools for data analysis Tasks. IEEE Trans. Vis. Comput. Graph. 2626, 1-30. https://doi.org/10.1109/TVCG.2017.2779501

Rodriguez, C.C.G., Colles, R., Antipolis, S., Lyon, U. De, 2012. Sensor data quality for geospatial monitoring applications 24-27

Rueda, C., Gertz, M., 2008. Real-time integration of geospatial raster and point data streams. Lect. Notes Comput. Sci. (including Subser. Lect. Notes Artif. Intell. Lect. Notes

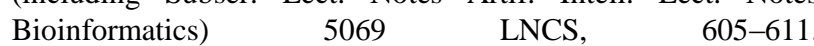
https://doi.org/10.1007/978-3-540-69497-7_45

Samson, G.L., Lu, J., 2016. University of huddersfield repository original citation large spatial datasets: Present challenges , future opportunities.

Sanchez, A., Rivera, W., 2017. Big data analysis and visualization for the smart grid. 2017 IEEE Int. Congr. Big Data (BigData Congr. 414-418. https://doi.org/10.1109/BigDataCongress.2017.59

Silva, S.F., Catarci, T., 2000. Visualization of linear timeoriented data: A survey. Proc. 1st Int. Conf. Web Inf. Syst. Eng. WISE $\quad 2000 \quad 1, \quad 310-319$. https://doi.org/10.1109/WISE.2000.882407

Singh, D., Vishnu, C., Mohan, C.K., 2017. Visual big data analytics for traffic monitoring in smart city. 15th IEEE Int. Conf. Mach. Learn. Appl. ICMLA 2016 886-891. https://doi.org/10.1109/ICMLA.2016.177

Southworth, F., Peterson, B.E., 2000. Intermodal and international freight network modeling. Transp. Res. Part C Emerg. Technol. 8, 147-166. https://doi.org/10.1016/S0968090X(00)00004-8

Stasch, C., Foerster, T., Autermann, C., Pebesma, E., 2012. Spatio-temporal aggregation of European air quality observations in the Sensor Web. Comput. Geosci. 47, 111-118. https://doi.org/10.1016/j.cageo.2011.11.008

Stefan, M., Lopez, J.G., Andreasen, M.H., Olsen, R.L., 2017. Visualization techniques for electrical grid smart metering data: A survey. Proc. - 3rd IEEE Int. Conf. Big Data Comput. Serv. Appl. BigDataService 2017 165-171. https://doi.org/10.1109/BigDataService.2017.26

Stratigea, A., Papadopoulou, C.-A., Panagiotopoulou, M., 2015. Tools and technologies for planning the development of smart cities. J. Urban Technol. 22, 43-62. https://doi.org/10.1080/10630732.2015.1018725

Sugumaran, V., Sugumaran, R., 2007. Web-based Spatial Decision Support Systems (WebSDSS): evolution, architecture, examples and challenges. Commun. Assoc. Inf. Syst. 19, 844875
Sun, D.H., Sang, C.Y., 2014. Nonnegative matrix factorizationbased spatial-temporal clustering for multiple sensor data $\begin{array}{lllll}\text { streams. } & \text { J. } & \text { Sensors } & \text { 2014, } & \text { 12 }\end{array}$ https://doi.org/10.1155/2014/824904

Sun, G.D., Wu, Y.C., Liang, R.H., Liu, S.X., 2013. A survey of visual analytics techniques and applications: State-of-the-art research and future challenges. J. Comput. Sci. Technol. 28, 852867. https://doi.org/10.1007/s11390-013-1383-8

Sun, Y., Li, S., 2016. Real-time collaborative GIS: A technological review. ISPRS J. Photogramm. Remote Sens. 115, 143-152. https://doi.org/10.1016/j.isprsjprs.2015.09.011

Tan, S., Yang, J., Yan, J., Lee, C., Hashim, H., Chen, B., 2017. A holistic low carbon city indicator framework for sustainable development. Appl. Energy 185, 1919-1930. https://doi.org/10.1016/j.apenergy.2016.03.041

Thomas, J.J., Cook, K.A., 2005. Illuminating the path: The research and development agenda for visual analytics. IEEE Comput. Soc. 184. https://doi.org/10.3389/fmicb.2011.00006

Thomson, J., Hetzler, E., Maceachren, A., Gahegan, M., 2005. A typology for visualizing uncertainty. Vis. Data Anal. 5669, 146157. https://doi.org/10.1117/12.587254

Toth, C., Jóźków, G., 2016. Remote sensing platforms and sensors: A survey. ISPRS J. Photogramm. Remote Sens. 115, $22-$ 36. https://doi.org/10.1016/j.isprsjprs.2015.10.004

Trindade, E.P., Hinnig, M.P.F., da Costa, E.M., Marques, J.S., Bastos, R.C., Yigitcanlar, T., 2017. Sustainable development of smart cities: a systematic review of the literature. J. Open Innov. Technol. Mark. Complex. 3, 11. https://doi.org/10.1186/s40852017-0063-2

Tsolakis, N., Anthopoulos, L., 2015. Eco-cities: An integrated system dynamics framework and a concise research taxonomy. Sustain. Cities Soc. 17, 1-14. https://doi.org/10.1016/j.scs.2015.03.002

Tunio, S., Kazi, H., Qureshi, S., 2017. Customization of graphical visualization for health parameters in health care applications. Int. J. Adv. Comput. Sci. Appl. 8, 91-95

Urban, A.R., Liu, Y., Hill, D., Rodriguez, A., Marini, L., Kooper, R., Myers, J., Wu, X., Minsker, B., 2009. Data-driven geospatial visual flooding decision support

Vanus, J., Kucera, P., Martinek, R., Koziorek, J., 2014. Development and testing of a visualization application software, implemented with wireless control system in smart home care. Human-centric Comput. Inf. Sci. 4. https://doi.org/10.1186/s13673-014-0019-5

Wang, W., De, S., Zhou, Y., Huang, X., Moessner, K., 2017. Distributed sensor data computing in smart city applications. 18th IEEE Int. Symp. A World Wireless, Mob. Multimed. Networks, WoWMoM 2017 